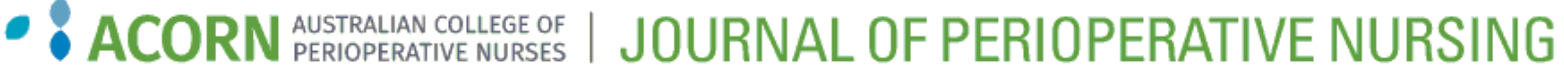

Volume 35

Issue 1 Journal of Perioperative Nursing

Article 5

2-28-2022

\title{
Where are the practising nurse anaesthetists in Australia? Exploring an advanced practice role for anaesthesia nurses
}

Follow this and additional works at: https://www.journal.acorn.org.au/jpn

Part of the Perioperative, Operating Room and Surgical Nursing Commons

(c) (i)

This work is licensed under a Creative Commons Attribution 4.0 License.

\section{Recommended Citation}

Michaels, Lucy and Foran, Paula (2022) "Where are the practising nurse anaesthetists in Australia? Exploring an advanced practice role for anaesthesia nurses," Journal of Perioperative Nursing: Vol. 35 : Iss. 1 , Article 5.

Available at: https://doi.org/10.26550/2209-1092.1183

https://www.journal.acorn.org.au/jpn/vol35/iss1/5

This Discussion paper is brought to you for free and open access by Journal of Perioperative Nursing. It has been accepted for inclusion in Journal of Perioperative Nursing by an authorized editor of Journal of Perioperative Nursing. 


\author{
Authors \\ Lucy Michaels \\ MCN (Anaesthetic \& Recovery Nursing), \\ GradDipN (Anaesthetic \& Recovery \\ Nursing), BN, RN, MACPAN, MACORN \\ Dr Paula Foran \\ PhD, RN, FACORN, FACPAN, MACN
}

\title{
Where are the practising nurse anaesthetists in Australia? Exploring an advanced practice role for anaesthesia nurses
}

\begin{abstract}
The perioperative environment has seen the implementation of the perioperative nurse surgical assistant as an advanced practice nursing role for the instrument nurse; however, there is currently no recognised equivalent role for the anaesthesia nurse. Anaesthesia nurses complete post-graduate qualifications and learn advanced clinical skills, and yet the authoritative body for perioperative nurses, the Australian College of Perioperative Nurses, does not define a specific role for advanced practice nursing in anaesthesia. Career advancement for the anaesthesia nurse focuses on education and management roles which are a distinct deviation from advanced clinical practice. A new role should be developed to allow the advanced practice nurse in anaesthesia to be recognised and their skills used in Australian operating rooms.
\end{abstract}

Keywords: nurse anaesthetist, non-medical anaesthesia provider, certified registered nurse anaesthetist (CRNA), advanced practice nurse, anaesthetic nurse, anaesthesia nurse

\section{Introduction}

Modern anaesthetic agents, such as nitrous oxide, ether and chloroform, were first used by dentists and physicians in the United States of America (USA) and Great Britain specifically to provide pain relief during dental and medical procedures. Seen as being safer for patients, ether quickly became the preferred anaesthetic agent and, due to its ease of administration, nurses were able to take the lead in administering it. Similarly in France, nurses were trained to administer ether, unsupervised by physicians, to provide anaesthesia for the army during World War $1{ }^{2}{ }^{2}$ but it was the American influence that set the stage for nurse anaesthetists to become a bona fide profession in their own right.

In contrast, British nurses were unable to carve themselves a niche in anaesthesia delivery - perhaps due to the British preference for chloroform which was inherently more dangerous and difficult to administer - and the nurse anaesthetist role was lost to physicians. In 2018, Tenedios et al. described the administration of anaesthesia in Britain as being limited to surgeons, physicians and physicians' assistants, to the complete exclusion of nurses. ${ }^{2}$ Australia and Britain are two of the countries in a small group that continue to allow nurses to assist with anaesthesia delivery but not to administer it.

In the Australian perioperative environment, the anaesthetic team consists of an anaesthetist and their assistant - an anaesthesia nurse or anaesthetic technician. ${ }^{3}$ The anaesthesia nurse is described by the Australian College of Perioperative Nurses (ACORN) as 
a dual role providing both nursing care to the patient and quality assistance to the anaesthetist during the critical moments of anaesthesia. ${ }^{4}$ The ACORN standard 'Advanced practice nursing and nurse practitioner roles' does not discuss an advanced role for the anaesthesia nurse. ${ }^{5}$ The Australian and New Zealand College of Anaesthetists (ANZCA) is the governing body responsible for the training and assessment of anaesthetists; ANZCA's current stance is that delivering anaesthesia is a medical role that requires completion of a specialty anaesthesia training program. ${ }^{6}$ While ANZCA does acknowledge there are benefits for patients related to the inclusion of non-medical personnel with advanced anaesthetic skills in the perioperative team, there is currently no role in Australia that allows anaesthesia nurses to practice anaesthesia with any further autonomy. ${ }^{6}$

Thematic analysis was completed by reading articles until saturation had occurred and no new patterns or ideas were emerging. This discussion paper will examine this topic under the following themes: the anaesthesia nurse, advanced practice nursing in the perioperative environment, international models for nurse anaesthetists, an Australian model for advanced practice anaesthesia nursing, career progression for the anaesthesia nurse and barriers to implementation.

\section{Discussion}

\section{The anaesthesia nurse}

ACORN and ANZCA guidelines require the anaesthetic assistant to meet the criteria in the ANZCA professional standard PS08 'Position statement on the assistant for the anaesthetist'.,3 This position statement states that training must include education in several core competencies and a combination of assessments and practical experience. ${ }^{3}$ Once these requirements have been met the nurse assistant must also participate in continuous anaesthesia-specific professional development in addition to meeting their annual registration requirements to practice in this role. ${ }^{4,7}$ While anaesthesia nurses can choose to undertake postgraduate study and complete advanced skill certifications through organisations such as the Australian College of PeriAnaesthesia Nurses (ACPAN), there is no defined advanced practice nursing role directly linked to formal education for the anaesthesia nurse to progress to in the Australian perioperative environment. ${ }^{5}$ Other avenues of career advancement lead into management and education roles which involve a reduction in clinical practice - a study by Nurmeksela et al. found that clinical duties were described as the activity performed least in the day-to-day nurse manager role.

\section{Advanced practice nursing in the perioperative environment}

An advanced practice nurse has acquired an expert knowledge base, complex decision-making skills and additional clinical competency through the completion of further education.10,11 In the perioperative environment, the experienced instrument nurse can pursue additional education and qualify for the role of the perioperative nurse surgical assistant (PNSA), which allows them to assist with performing surgical interventions and provide enhanced pre- and post-operative care under the supervision of the surgeon. ${ }^{11,12}$ ACORN describes the PNSA as a registered nurse who practices at an advanced level to provide extended perioperative nursing care. This non-medical surgical assistant role is seen as a direct extension of the instrument nurse role.11 Qualification as a PNSA can be gained as part of a Master of Nursing or as a tertiary short course for registered nurses who have previously completed a Master of Nursing. ${ }^{13}$ Despite confusion about the scope of practice and remuneration for the PNSA, Haines and Smith describe non-medical clinicians as being valuable in the perioperative space, particularly where there is limited access to medical practitioners.12 Given that this advanced practice nursing avenue already exists for the instrument nurse, it seems reasonable to consider an advanced practice role for the anaesthesia nurse to allow an equal opportunity for career development.

\section{International models for nurse anaesthetists}

The USA and Europe both provide a greater scope of practice for nurses and other non-medical anaesthesia providers in roles such as nurse anaesthetist, anaesthesiologist assistant and physician assistant who are able to deliver anaesthesia under the supervision of an anaesthetist., 6,14 A 1999 seminal study by McAuliffe and Henry aimed to provide a baseline of data for nurse-delivered anaesthesia worldwide. 15 McAuliffe and Henry reported that nurses were delivering anaesthesia in 107 countries and performing tracheal intubation, regional anaesthesia and intra-operative management, either independently or under the direct or indirect supervision of medical anaesthesia providers..$^{15}$ In many low-income countries such as Ethiopia, Kenya and Liberia, nonphysician anaesthesia providers are the sole anaesthesia provider available and deliver safe anaesthetic care to thousands of patients every year. ${ }^{10,16}$ The American Association of Nurse Anesthesiology (AANA) state that in the USA Certified Registered 
Nurse Anaesthetists (CRNAs), who have been credentialled since 1956, administer more than 50 million anaesthetics per year and represent 80 per cent of the anaesthesia providers in rural America."

\section{An Australian model for advanced practice anaesthesia nursing}

In Australia, one avenue of further education for anaesthesia nurses is a postgraduate certificate or diploma, followed by a master's degree specialising in anaesthetic nursing. ${ }^{18}$ Anaesthesia nurses may also choose to pursue advanced clinical skills certifications through professional organisations such as ACPAN. However, none of these qualifications leads to a recognised advanced anaesthesia nursing practice role in the perioperative environment. ${ }^{5}$ To proceed with the development of an advanced practice role in Australia the educational requirements described by the International Federation of Nurse Anesthetists (IFNA) would need to be carefully examined.19 In 2021 the International Council of Nurses (ICN) released the Guidelines on Advanced Practice Nursing Nurse Anesthetists that were developed in collaboration with the IFNA. ${ }^{10}$ These guidelines aim to support the nurse anaesthetist role in assisting with the ambitious World Health Organization aim of ensuring that five billion people around the world will be able to access safe and affordable surgical and anaesthesia care by $2030 .^{10}$ These guidelines also require the nurse to complete a master's level qualification in anaesthesia education that includes clinical practice, a thesis and a comprehensive examination process to practice as a nurse anaesthetist.10 There is currently no comparable master's course available in Australia; and, when planning an advanced anaesthesia nursing practice role, a suitable tertiary institute that would collaborate closely with ACORN and ANZCA would need to be identified.

The ICN guidelines aim to provide clarity for the nurse anaesthetist role, as it develops, and assist organisations with creating policies and frameworks to support the governance and practice of nurse anaesthetists. $^{10}$ The ICN describes nurse anaesthetists as caring for patients during every step of the perioperative journey, and their scope of practice includes performing preanaesthesia assessment; prescribing pre-medication; administering anaesthetic drugs, fluids and blood products; managing perioperative complications; facilitating emergence from anaesthesia, and managing post-operative pain. ${ }^{10}$ An Australian model of advanced practice anaesthesia nursing would need to be developed from the ICN guidelines working closely with all relevant parties to ensure that the role has a clear credentialing process and appropriate professional standards to work within. A scope of practice that enables the anaesthesia nurse to work collegially with specialist anaesthetists as a valued member of the anaesthesia team would also need to be carefully developed and negotiated with all stakeholders.

In an older Australian trial, the Royal Adelaide Hospital incorporated physician assistants into their perioperative anaesthesia care team to perform pre-anaesthetic assessment and treatment of patients with significant medical comorbidities who did not meet the requirements to be seen in 'high risk' clinics. ${ }^{20}$ Data from 231 patients examined by an external evaluation agent revealed that the physician assistants were able to successfully identify and manage an average of 2.5 medical issues per patient prior to surgery that otherwise would not have been realised until the day of their admission..$^{20}$ This improved perioperative efficiency and demonstrated the potential value of incorporating non-medical anaesthesia providers into the anaesthetic team..$^{20}$ The Australian advanced practice anaesthesia nurse role could be introduced in a similar way that focuses on specific stages of perioperative care, such as preanaesthesia assessment or postoperative outreach. This advanced practice nursing role would have a greater scope of practice, higher level of autonomy and increased critical decision-making than anaesthesia nurses currently have and would remain under the direct or indirect supervision of a specialist anaesthetist, similar to the PNSA working under the supervision of the surgeon.

\section{Career progression for the anaesthesia nurse}

With the Department of Health in Australia predicting a shortfall of almost 45000 nurses in Australia by 2030 as a result of increased demand and a steadily growing attrition rate, retention of experienced nurses is vital to maintain an adequately skilled nursing workforce. ${ }^{21}$ Other countries have demonstrated that job dissatisfaction is closely linked to high attrition rates in nursing with Sillero-Sillero and Zabalegui finding that 20 per cent of perioperative nurses in a large Spanish public hospital would resign if the chance arose, with 94.9 per cent citing dissatisfaction with professional development opportunities as one of the main reasons for overall job dissatisfaction.22 A study of 113 Canadian perioperative nurses by Lee et al. also found that decreased job satisfaction was strongly linked to the intention of nurses to leave the profession. $^{23}$

A survey of 1365 Australian nurses conducted in 2013 found that a lack 
of career options was also one of the main reasons for job dissatisfaction among nurses in Queensland. ${ }^{24}$ In this study 13.8 per cent of nurses were dissatisfied or very dissatisfied with their career progression, with respondents contemplating leaving the profession stating a lack of career advancement and advanced practice nursing roles as the main reasons for dissatisfaction, and that nonclinical roles, such as management, were often the only option for career progression. ${ }^{24}$ These figures do not take into account any unanticipated reductions in recruitment from migration which will potentially be significantly affected by the COVID-19 pandemic. $^{25}$

Negrusa et al. examined the findings of the 2019 AANA survey of CRNAs and found that 89 per cent of CRNAs in the USA were satisfied or somewhat satisfied in their job, with a higher level of autonomy listed as a factor associated with increased job satisfaction. ${ }^{26}$ Lee et al. also found that strong collegial relationships between perioperative nurses and physicians were strongly linked to higher levels of job satisfaction $(p<.05) .{ }^{23}$ A 2015 study of 24 Australian PNSA course graduates cited professional development, a desire to provide a higher quality of patient care and gaining formal recognition as the main reasons for pursuing the PNSA qualification. ${ }^{27}$ Creating an advanced practice role in Australia may allow anaesthesia nurses the same opportunity to provide a higher level of patient care, build greater autonomy and develop more reciprocal clinical relationships with anaesthetists, leading to increased levels of job satisfaction and a higher rate of retention.

\section{Barriers to advanced practice anaesthesia nursing}

Future advanced practice anaesthesia nurses can learn from the barriers experienced during the implementation of the PNSA and other non-medical perioperative roles in Australia. In 2012, Willows wrote about his experience as the inaugural PNSA at the Royal Hobart Hospital and described a reluctance to recognise the role, issues with remuneration and hostility from both nursing and medical staff as being significant barriers to implementation, although he found the role itself was greatly rewarding." Hains and Smith discussed how the protectionism of medical roles in the perioperative space limits the opportunities for nurse practitioners as surgical assistants to gain adequate exposure and experience, and work to their full scope of practice.12 A 2020 study performed by Weinberg et al. in a large Australian hospital found, to the great surprise of the authors, that most specialist anaesthetists did not support a nurse practitioner model for the delivery of sedation for endoscopy procedures, nor were they willing to participate in the training and supervision of nurse practitioners in anaesthesia. ${ }^{28}$ Reasons cited were a perceived compromise to patient safety, a potential for increased public liability, reduced opportunities for anaesthetists in training and low consumer acceptance, despite the hypothesised benefits of improved patient access to vital endoscopy services. ${ }^{28}$ The 60 specialist anaesthetists who participated in the survey also made it very clear that the development of a model of care that allows non-medical anaesthesia providers to perform sedation would require careful negotiation with ANZCA. ${ }^{28}$
From 2017 to 2018, Australian public hospitals spent 60 per cent of their total funding on wages, with private hospitals in Australia reporting spending just over 49 per cent. ${ }^{29}$ In the year 2000, Glance modelled several different staffing scenarios in the US to determine if the cost effectiveness of anaesthesia delivery could be improved by changing the skill mix of anaesthesiologists and CRNAs. ${ }^{30}$ This study determined that a model that carefully balances the ratio of physician and non-physician anaesthesia providers according to patient risk would result in more cost effective anaesthesia services without increasing the overall mortality rate, although a larger sample size would be required to validate these findings. ${ }^{30}$ With the demand for surgical and diagnostic services in Australia increasing,, ${ }^{29}$ the addition of a carefully balanced ratio of advanced practice anaesthesia nurses working in collaboration with specialist anaesthetists may provide a more economical way to increase the capacity of the anaesthesia workforce. ${ }^{30}$ While the Department of Health in Australia is currently estimating a small oversupply of anaesthetists by 2030, this is based on maintaining current levels of anaesthetist migration and does not take into account the possible effects of the COVID-19 pandemic. ${ }^{31}$

\section{Conclusion}

Advanced practice nursing roles in the perioperative environment provide nursing staff with the opportunity to gain formal recognition for knowledge and skills and higher levels of job satisfaction. The current lack of an advanced practice role for anaesthesia nurses needs to be addressed to provide the anaesthesia nurse with professional equity in the Australian perioperative environment. However, advanced practice roles 
for anaesthesia nurses in Australia depend heavily on the government, for support, and on regulatory bodies to provide appropriate recognition and remuneration. To be successful and have a meaningful impact on the provision of anaesthesia services in Australia, these advanced practice nurses would also require unwavering commitment from nursing and medical organisations. As long as there continue to be adequate supplies of specialist anaesthetists there will be resistance to the introduction of new roles in anaesthesia and it will be difficult to find a place for the non-medical anaesthesia provider in Australia without genuine and widespread support from the anaesthetist community. Ultimately, the implementation of an advanced practice role for anaesthesia nurses would provide an additional and economical string to the bow of anaesthesia care for patients in Australia.

\section{Acknowledgment}

This paper was submitted to the University of Tasmania as part fulfilment of subject CNA803, Advanced Clinical Nursing Practice, for the Master of Clinical Nursing (Anaesthetic and Recovery Nursing). The author sincerely wishes to thank Dr Paula Foran, unit coordinator, for her guidance throughout the master course and work in preparing this paper for publication.

\section{References}

1. Vigil-Fowler M, Hillman S, Desai S. Who controls the power over pain? A comparative history of nurse anaesthesia. Can Bull Med Hist 2019;36(2):308-45

2. Tenedios C, O'Leary S, Capocci M, Desai S. History of anaesthesia: Nurse anaesthesia practice in the G7 countries (Canada, France, Germany, Italy, Japan, the United Kingdom and the United States of America). Eur J Anaesthesiol. 2018;35(3):158-64.
3. Australian and New Zealand College of Anaesthetists (ANZCA). PS08(A) Position statement on the assistant for the anaesthetist [Internet]. Melbourne: ANZCA; 2016 [cited 2021 Sep 14]. Available from: www.anzca.edu.au/getattachment/473f7e0db14a-4939-aad1-034c0474c603/PS08(A) Position-statement-on-the-assistant-forthe-anaesthetist

4. Australian College of Perioperative Nurses (ACORN). Anaesthetic nurse. In: Standards for perioperative nursing in Australia: Professional standards. Adelaide: ACORN: 2020

5. Australian College of Perioperative Nurses (ACORN). Advanced practice nursing and nurse practitioner roles. In: Standards for perioperative nursing in Australia: Professional standards. Adelaide: ACORN: 2020.

6. Australian and New Zealand College of Anaesthetists. PS08(A)BP Position statement on the assistant for the anaesthetist: Background paper [Internet]. Melbourne: ANZCA; 2016 [cited 2021 Sep 14]. Available from: www.anzca.edu.au/getattachment/ c3657808-f7eb-48c8-a682-182de3351588 PS08(A)BP-Position-statement-on-theassistant-for-the-anaesthetist-BackgroundPaper

7. Nursing and Midwifery Board of Australia (NMBA). Registration standard: Continuing professional development [Internet]. Melbourne: NMBA; 2016 [cited 2021 Sep 21]. Available from: www.nursingmidwiferyboard.gov.au/ documents/default.aspx?record= WD16\%2f19507\&dbid=AP\&chksum $=$

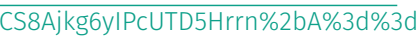

8. Australian College of PeriAnaesthesia Nurses (ACPAN). For anaesthesia and post anaesthesia nurses [Internet]. Melbourne: ACPAN; 2021 [cited 2021 Sep 21]. Available from: www.acpan.edu.au

9. Nurmeksela A, Mikkonen S, Kinnunen J, Kvist T. Relationships between nurse managers' work activities, nurses' job satisfaction, patient satisfaction, and medication errors at the unit level: A correlational study. BMC Health Service Research 2021;21(1):296.

10. International Council of Nurses (ICN). Guidelines on advanced practice nursing nurse anesthetists [Internet]. ICN; 2021 [cited 2021 Sep 21]. Available from: www.icn.ch/system/files/2021-07/ICN_ Nurse-Anaesthetist-Report_EN_WEB.pdf

11. Willows R. Perioperative nurse surgeon assistant (PNSA) role within the cardiothoracic unit (CTU) of Royal Hobart Hospital. Day Surg Australia 2012;11(1):10-1.
12. Hains T, Smith C. What is the scope of practice of the nurse practitioner as a surgical assistant in Australia? JPN. 2020;33(3):e16-e21.

13. La Trobe University. Perioperative nurse surgical assistant (PSNA) [Internet]. Melbourne: La Trobe University; 2021 [cited 2021 Sep 21]. Available from: www.latrobe.edu.au/courses/short-courses/ perioperative-nurse-surgical-assistant

14. Australian Society of Anaesthetists (ASA) Basic information [Internet]. Sydney: ASA; 2021 [cited 2021 Sep 21]. Available from: www.asa.org.au/basic-information/

15. Henry B, McAuliffe M. Practice and education of nurse anaesthetists. Bulletin of the World Health Organization. 1999;77(3):267-70.

16. Odinkemelu D, Sonah A, Nsereko E, Dahn B, Martin M, Moon T. An assessment of anesthesia capacity in Liberia: Opportunities for rebuilding post-Ebola. Anesth Analg 2021;136(6):1727-37.

17. American Association of Nurse Anesthesiology (AANA). CRNA fact sheet [Internet]. Park Ridge: AANA; 2021 [updated 2022 Jan 20; cited 2021 Sep 21]. Available from: www.aana.com/membership/becomea-crna/crna-fact-sheet

18. University of Tasmania (UTAS). Master of clinical nursing (specialisation) [Internet]. Hobart: UTAS; 2021 [cited 2021 Sep 21] Available from: www.utas.edu.au/courses/ chm/courses/h7f-master-of-clinicalnursing-specialisation

19. International Federation of Nurse Anesthetists (IFNA). Master's model curriculum [Internet] France: IFNA; 2021 [cited 2021 Sep 21]. Available from: www.ifna.site/download/masters-modelcurriculum/

20. Ludbrook G, T P. Physician assistants in perioperative medicine. Australasian Anaesthesia. 2009:111-3.

21. Health Workforce Australia. Australia's future health workforce - nurses overview report. Canberra: Commonwealth of Australia; 2014.

22. Sillero-Sillero A, Zabalegui A. Analysis of the work environment and intention of perioperative nurses to quit work. Rev Latino-Am Enfermagem. 2020;28:e3256-330.

23. Lee S, MacPhee M, Dahinten V. Factors related to perioperative nurses' job satisfaction and intention to leave. Japan J Nurs Sci. 2020;17(1).

24. Eley R, Francis K, Hegney D. Career progression: The views of Queensland's nurses. Aust J Adv Nurs 2013;4:23-31.

25. Stievano A, Bakhshi M, Shaffer FA, Hamilton D. Ethical challenges and nursing recruitment during COVID-19. Nursing Ethics 2021;28(1):6-8. 
26. Negrusa S, Hogan P, Jordan L, Hoyem R, Cintina I, Zhou M et al. Work patterns,

socio-demographic characteristics and job satisfaction of the CRNA workforce - findings from the 2019 AANA survey of CRNAs. Nurs Outlook 2019;69(3):370-9.

27. Lynn A, Brownie S. The perioperative nurse surgeon's assistant: Issues and challenges associated with this emerging advanced practice nursing role in Australia. Collegian 2015;22(1):109-15.

28. Weinberg L, Grover H, Cowie D, Langley E, Heland M, Story D. Attitudes of anesthetists towards an anesthesia-led nurse practitioner model for low-risk colonoscopy procedures: A cross-sectional survey. Human Resourses for Health 2020;18(20)

29. Australian Institute of Health and Welfare (AlHW). Australia's hospitals at a glance 2018-2019 [Internet]. Canberra: AlHW; 2020 [cited 2021 Sep 21]. Available from: www.aihw.gov.au/getmedia/c14c8e7f-70a34b00-918c-1f56d0bd9414/aihw-hse-247.pdf. aspx?inline=true

30. Glance L. The cost effectiveness of anesthesia workforce models: a simulation approach using decision-analysis modeling Anesth Analg 2000;3:584-92

31. Department of Health. Australia's future health workforce - anaesthesia. Canberra: Commonwealth of Australia; 2016. 